\title{
American Journal of
}

\section{Health, Medicine and Nursing Practice}

(AJHMN)

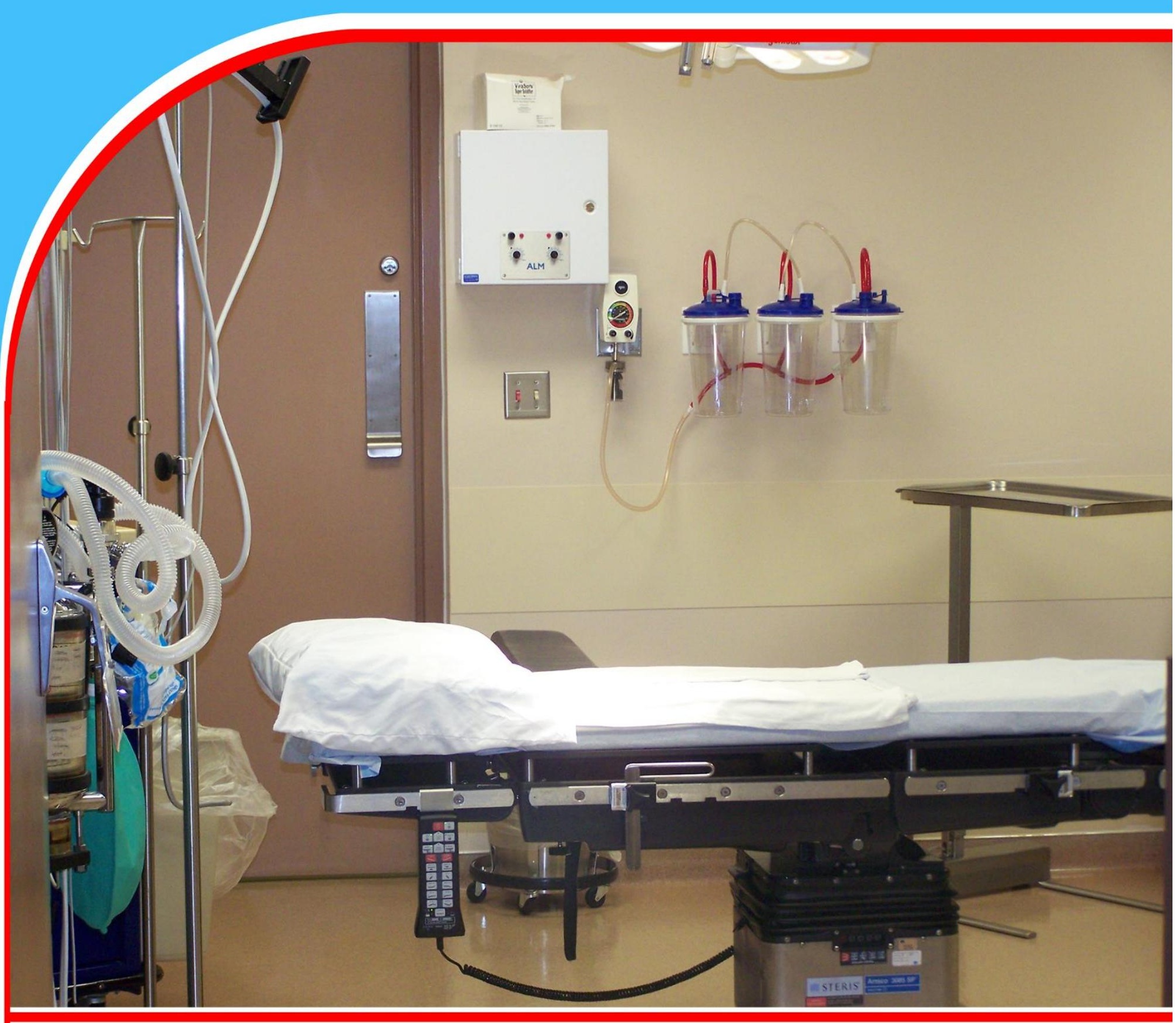

ADOPTION OF OCCUPATIONAL SAFETY AND HEALTH PRACTICES AMONG HEALTH CARE WORKERS IN KENYAN PUBLIC REFERRAL HOSPITALS

Nyariki Caroline Kemunto Chirchir Matthew Kimeli 


\title{
ADOPTION OF OCCUPATIONAL SAFETY AND HEALTH PRACTICES AMONG HEALTH CARE WORKERS IN KENYAN PUBLIC REFERRAL HOSPITALS
}

\author{
${ }^{1}$ Nyariki Caroline Kemunto \\ Moi Teaching and Referral Hospital Eldoret Kenya \\ carolinenyariki@mtrh.go.ke \\ ${ }^{2 *}$ Chirchir Matthew Kimeli \\ Kenya School of Government, Baringo, Kenya \\ *mathew.chirchir@ksg.ac.ke
}

\begin{abstract}
Purpose: The study sought to assess adoption of occupational safety and health practices among health care workers in Kenyan public referral hospitals, especially to establish the place of health care worker training, personal protective equipment, occupational safety and health standards in influencing adoption of occupational safety and health practices.

Methodology: The cross-sectional survey research study was based on data from 80 medical staff collected using a structured questionnaire from Baringo county referral hospital in Kenya. Data was diagnostically screened to determine Measure of Sampling Adequacy through KaiserMeyer-Olkin (KMO) and Bartlett's test of sphericity for detection of adequacy of correlations between the variables. Factor analysis was used as a dimensions reduction technique to identify predictors and principal components that accounted most for adoption of occupations safety and health practices among health care workers while Wald Chi-square test of model fit was used to determine if predictors in the principal components significantly influenced adoption of occupational safety and health practices while regression analysis was used to determine the relationship between principal components established through factor analysis.
\end{abstract}

Findings: The study concluded that from the total of 20 factors under study, seven factors accounted most in determining adoption of occupational safety and health practices among health care workers in Kenyan public referral hospitals; they are staffed capacity building through training, implementation of safety and health guidelines, wearing of safety gear, provision of standard operating procedures on PPEs, training needs analysis, provision of information to staff on guidelines and sensitization on risks.

Unique contributions to practice and policy: The study recommends that, County Executive Committee member for health through the Medical Superintendent should make necessary budgetary allocations towards staff training, organize and implement specialized training in occupational safety and health for their staff as a matter of priority. The medical superintendent should put in place a robust mechanism that ensures consistent implementation of safety and health guidelines in their facilities. He should further cause an audit of PPEs and ensure deficits on PPEs are included in the next and subsequent financial year procurement plan. The Human Resource Officers should on continuous basis utilizing continuous education approach, organise staff sensitization particularly to sensitize staff on wearing of safety gear, standard operating procedures on PPEs and preview of applicable guidelines and sensitization on risks.

Keywords: Occupational safety, Healthcare workers, Referral hospitals 


\section{INTRODUCTION}

Occupational health and Safety is a cross cutting disciplinary area aimed at protecting the safety, health and welfare of people engaged in work or employment. Health workers are core pillars of sustainable social and economic development of any given society and they play a vital role in the functioning of a given health system. In most cases the focus is on care consumers rather than the caregivers (Adamu \& Abdulahi, 2017).

ILO (2008) estimates, the global number of work-hazards does not seem to have changed significantly during the past 10 years. These are mainly driven by the globalization process and by rapid industrialization in relatively poor countries that are not capable of maintaining effective OSH systems. It has thus been argued that the requirement to target health and safety is as preponderant as ever. Healthcare professionals, especially those working in surgical services, environmental services and sterile processing, are exposed to a significant number of chemicals, including those used to clean and disinfect the healthcare environment and those used to disinfect and sterilize surgical instruments and medical device. Other hazards include blood-borne pathogen transmissions caused by sharps injuries, as well as respiratory dangers associated with the inhalation of surgical smoke and other particles (Brunner \& Suddarths, 2007).

The most effective way to control health hazards among Hospital workers is to comply with occupational safety and health standards in hospital and make safety a prime priority (OSHA, 2007). Moreover, poor safety awareness, Poor training and acceptance of safety practise may worsen the situation (Melissa, 2014; Orme et al., 2014). The level of hospital safety climate and safe working environment largely depends on legislation and compliance level of occupational safety policy and inspection of workplace environment to ensure practice of safety and health standards. The common health hazards found in health facilities are physical, biological, chemical, thermal, toxic and stress related problems. Prolonged standing or sitting may cause a lot of strain; injury may result from working accident or falls. Health care workers' safety and health is vital ingredient to healthy and productive society (Mehraj et al., 2011; Arocena, Nune \& Villanueva, 2008).

In most Sub Saharan African Countries, there are problem of insufficient health workers leads to overuse of the limited work force, resulting in work-related stress making officers vulnerable of needle stick injuries and cuts. Kenya, among other developing countries is yet to develop a good surveillance system for occupational exposure to health hazards in health institutions, hence limiting estimation of the exact magnitude of such hazards. There is little information on rate of compliance with universal precautions among health care workers, especially in high risk sections, moreover, occupational risk are even higher due to harsher working conditions, bigger isolation and insecurity, poorer infrastructure, inadequate instrumentation, and work overload (Matsiko, 2010).

According to International Labor Organization, (2011) workplace accidents and errors cost organizations, hundreds of billions of dollars each year, and the injured workers and their families endure considerable financial and emotional suffering. In the reviewed OSH act 2007, workers are required to abide by guidelines, SOPs and regulations governing occupational 
American Journal of Health, Medicine and Nursing Practice

ISSN 2520-4017 (Online)

Vol.4, Issue 1 No.1, pp 1 - 17, 2019

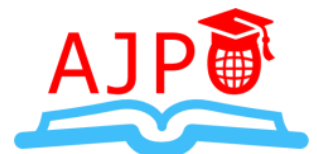

www.ajpojournals.org

safety and health in the workplace. The ministry of health has put in place provisions and safety guidelines that govern all operations and procedures to ensure safety at the work place.

\section{Statement of the Problem}

The International Labour Organization (ILO) findings revealed that work-related diseases and accidents account for economic losses are as high as 4\% of worldwide GDP (ILO, 2003). Occupational health interventions in some countries, especially Africa formed focal current issues. The World Health Organization (WHO) Sixtieth World Health Assembly (WHA) in 2007 endorsed the global plan of action on workers' health 2008-2017 with the name of and urged member states to work hard towards full coverage, especially the underserved workers in informal sectors, small and medium-sized enterprises, agriculture, migrant and contractual workers.

The nature of health care work; handling patients or investigating client's illness condition, makes it absolutely vital that safety and health are priorities. The extent to which health institutions allocate their limited resources towards occupational safety and health interventions, including both worksite health promotion and safety and health interventions, are driven by some combination of legal, financial, and moral factors (Adema \& Ladaique, 2009).

Despite the international commitment and the existence of a number of legal, legislative and regulatory provisions, adoption of occupational safety and health practices among health care workers is still wanting. Health workers continue to be adversely affected by biological, physical, chemical, and psychosocial occupational hazards they face in their workplace. In spite of world, national, regional, and native initiatives to develop a talented health force to deliver higher health outcomes, efforts to cut back OSH risks for medical experts in developing countries area unit aloof from comfortable to safeguard their health. Notably for developing countries facing a health force shortage, saving lives shouldn't be accomplished by sacrificing providers' own life. Particularly in Kenya, without healthy, well-prepared, motivated workers, the Universal Health Coverage for all cannot be achieved.

A Study on occupational health hazards among health workers conducted by Ndejjo et al. (2015) in Uganda; showed an increased number of cases of occupational hazards. A cross sectional survey, (Kurt et al., 2010) found that majority of health care workers were aware of policies and procedures for reporting accidents. A study conducted in Mbagathi Hospital Kenya revealed low adherence to National Infection Prevention and Control guidelines (Amadu \& Saka, 2010).

Several studies have indicated the need to identify major and critical areas that have more likelihood of causing hazards, as well as strategies to avoid them, so that the health of these workers is not affected. The sustainability of the health care system and productive outcome depends on the maintenance of workers' health, working capacity, safe working environment and the development of work organization and culture (Joan, 2010; Annalee et al., 2007). There is hardly any substantial empirical evidence on factors influencing the adoption of occupational health and safety practices among health workers, particularly in developing countries, hence need to undertake this study in an effort to bridge this gap. 
The broad objective of this study was therefore to assess the factors influencing the adoption of occupational safety and health practices among health workers at public referral hospitals in Kenya and especially to establish the place of health care worker training, Personal Protective Equipment, standards on occupational safety and health in influencing adoption of occupational safety and health practices among health workers at public referral hospitals in Kenya

\section{REVIEW OF LITERATURE AND EMPIRICAL STUDIES}

Anchoring the study on social cognition and safety climate theories, a review of literature and past empirical studies was undertaken on training, PPEs, Safety and health guidelines and Adoption of occupational safety and health practices among health care workers in Kenyan public referral hospitals.

\section{Training and Adoption of OSH Practices}

Training is the most effective approach to dealing with occupational health management issues. It is the cornerstone of preventive care and should be a priority by any employer (Rono, 2011). The design of health education program is to assist employees and employers to behave in a manner conducive to promotion, maintenance and restoration of health (Mejia, 2010). Organizations that are committed to the health of their employees invest greatly in educating their employees about the significance and meaning of healthy living (Brewer $e t$ al, 2010).

Primary methods of administering educational content include audio-visual materials, printed materials, and speakers hosting on-site seminars and web-based training. Health programs should broadly define the body of knowledge to include any adverse influence to an employee's mental and physical wellbeing and suggestions on how to counteract them (Rono, 2011). All employees should have information about infection, transmission and other aspects of health (Doebbeling \& Diekema, 1995). The topics to be covered should include accident and prevention, as well as nutrition, exercise and stress management (Brewer et al., 2010).

According to Cohen \& Colligan (1998), safety and health training at the workplace should be incorporated in the safety and health policies. This will give assurance of the organization's commitment to continually ensure its staff understands their work, hence reduce chances of accidents and injuries. Amponsah-Tawiah \& Mensah (2016) supports that health and safety programs need a clear definition of the policies and how training will take place to ensure safety performance. Law, Chan \& Pun (2006), posits that safety training as a component of knowledge that enables employees safely conduct their work without endangering themselves. AmposahTawiah \& Mensah (2016) believe that by effectively training employees, they become more accountable and ensure safety at their workplace.

According to Oluoch (2015), employers have an obligation to train staff, provide knowledge and experience to its staff for the safety and wellbeing of the employee in the workplace. O'Connor, Flynn, Weinstock \& Zanoni (2014) while acknowledging the importance of training in reducing occupational health, accidents and injuries, cautions against treating it in isolation from other interventions, they argue that workers should be trained on safety and also be allowed to demand for safety equipment and measures to be put in place in the organization. 
Robson et al. (2012) in their systematic review of the effectiveness of OHS training in Canada developed a conceptual model of workplace training interventions. The model shows that training interventions aimed at improving the skills of employee on matters of OHS are influenced by the individual factors, including learning style, cognitive ability, attitude and previous training. The immediate outcomes achieved from training are changes in behaviour, attitude, enhanced skills and motivation to act. These changes help in total control or minimization of hazard injuries, illness, machines and material damages, disabilities and costs associated with them. With such positive influence, employee morale is improved and thus enhanced work productivity.

A research carried out in two hospitals in Jamaica to assess the knowledge, compliance and practice of occupational infection control among health care workers found that health care workers were aware of the risk of transmission of infection, but their compliance with universal precautions was inadequate (Foster $e t$ at., 2010). 63\% of the health care workers were aware that utilizing needles for drawing blood could expose them to the transmission of infections but only $38 \%$ wore gloves. In this study, a comprehensive program to educate the healthcare workers regarding compliance with universal precautions was recommended to improve their knowledge and practice. Awareness of safety programs is beneficial to business operations, since the implementation of safety interventions significantly reduces direct health care cost and absenteeism (Bunn et al. 2001).

In Malaysia, a study conducted showed that the level of knowledge and awareness towards occupational safety and health (OSH) aspects among workers in a medical laboratory in Klang Valley was low with only $61 \%$ of the respondents being aware of the OSHA (AnuaretaI, 2009). Another study was also conducted among doctors, nurses, medical support staff and administrative officers who showed that the level of OSH awareness and knowledge among healthcare professionals in Malaysia was moderate (75\%) (LugahetaI, 2010). It also established that proportion of participants who had good OSH knowledge was low. A recommendation from this study was that healthcare organizations should conduct more workshops and raining for specific healthcare worker groups in order to increase knowledge of OSHA.

In a study conducted in Tanzania to assess the status of occupational safety among health service providers in hospitals by Manyele, Ngonyani \& Eliakimu (2008), it stated that none of the 430 respondents had received coaching on OHS as a profession. Limited information on the awareness of health care workers in OSH is available, but the situation in Tanzania and Nigeria reflects the occurrences in Kenya. It is apparent that healthcare workers at all levels are exposed to occupational injuries as well as diseases while performing their duties. Therefore, knowledgeable health care workers, especially those in charge of the health clinics are very important because they play a role in making sure that their workplaces are safe and in guiding staffs under them to take further actions if accidents happened to these staffs.

\section{Personal Protective Equipment (PPE) and Adoption of OSH Practices}

Use of protective devices when performing risky activities and maintenance of safe place of work are necessary precautionary measures against accidents (Steve, 2003). An employer should provide employees with appropriate personal protective equipment and clothing that is suitable for the work performed. Safety equipment at the workplace includes hard hats, safety glasses and goggles, rain gear, safety vests, work gloves, sensors for gas detectors, safety boots and shoes, flashlight and lanterns, first aid kit, sanitizers and cleaners, storm equipment cases 
and non-flammable safety cabinets. If there is a likelihood of fire or explosion in a confined space, an employer should ensure that no source of ignition is present in the space. Some common types of safety gear across all industries are work boots and safety gloves, and many of these are specific to the job requirements

Personal protective equipment is designed to protect the wearer's body from injury by blunt impacts, electrical hazards, heat, chemicals, and infection, for job-related occupational health and safety purposes. The use of personal protective equipment is necessary to reduce employee exposure to hazards when engineering and administrative controls are not feasible or effective to reduce these risks to acceptable levels. Safety includes more than just the type of equipment and protective gear (OSHA, 2007).

Kuhn (2015) examined the effectiveness of Personal Protective Equipment for Healthcare Workers caring for patients with Filovirus Disease; A rapid review, guided by a protocol, was conducted to inform development of WHO guidelines on personal protecting instrumentation within the context of the continuing (2013-present). Western African animal virus illness irruption, with attention on health care staff directly caring for patients with hemorrhagic fever or Marburg virus diseases. The study concluded that insufficient evidence exists to draw conclusions regarding the comparative effectiveness of various types of personal protective equipment. Additional research is urgently needed to determine optimal PPE for health care workers caring for patients with filovirus.

Lombardi et al. (2018) did a study to identify and describe the array of factors that influence a workers' decision to wear personal protective eyewear (PPE) and the barriers that exist in preventing their use. The study indicated Several potentially modifiable factors identified would lead to an increase in workers' PPE use and encourage supervisors to provide ongoing positive feedback for the continuous use of PPE by staff in danger for an eye related injury.

\section{Standards and Adoption of OSH Practices}

Rono (2011) posits that health and medical standards comprise decisions, plans, and actions undertaken to achieve specific health care goals within an organization. The occupational health policy defines the reason, roles and responsibilities of occupational health within the company, procedures and responsibilities of managers and employees (Hale et al., 2004). An explicit health policy defines a vision for the future, outlines priorities and the expected roles of different groups and builds consensus and informs people (WHO, 1950). There are many categories of health policies, including personal health care policy and pharmaceutical policy. They may cover topics of financing and delivery of health care, access to care, quality of care, and equity. OSH policies and regulations are there to guide on the safety practices to be followed to control the hazards workers are exposed to.

The modern concept of health care involves access to medical professionals from various fields as well as medical technology such as medications and surgical equipment's. It also involves access to the latest information and evidence from research, including medical research and health service research (Havold \& Nasset, 2009). Some organizations have an explicit policy or strategy to plan for adequate numbers, distribution, and quality of health workers to meet health care goals, such as to address physician and nursing shortages. 
A study assessing the safety practices by the health care workers in Nigeria showed that wearing hand gloves for clinical procedures was practiced by most $(96.2 \%)$ respondents, while an improvement is sought by those $(22.8 \%)$ that practice incorrect body positioning during clinical procedures. Surprisingly, only $52.1 \%$ "always" complied with preventive safety precautions advised in the standard operating procedures (SOPs) and job aids (Olufemi et al., 2016). The goal of all occupational safety and health standards is to foster a safe work environment and protect co-workers, family members, employers, customers, suppliers, nearby communities and other members of the public who are impacted by the workplace environment (OSHA, 2007).

\section{Adoption of occupational health and safety practices}

In Kenya, the Director of Occupational Safety and Health Services has the mandate to enforce compliance with the provisions of OSH Act (2007) at workplaces by ensuring that people obey a law or comply with it. Section 26 provides for appointment of occupational safety and health officers to assist the Director in enforcing compliance with occupational safety and health regulations. For this purpose, section 32(1) of the Act empowers an occupational safety and health officer to enter, inspect and examine, by day or by night, a workplace and every part thereof, which he has reasonable cause to believe that explosive, highly inflammable or any other hazardous materials are stored or used.

Alli (2008) posits that workers, employers and competent authorities have certain responsibilities, duties and obligations. For example, staff should follow established safety procedures; employers should offer safe workplaces and update occupational safety and health policies. Standard precautions reduce the risk of exposure to blood and body fluids Ho et al. (2002).

Enforcement and organizational trust through regular support supervision, provision of personal protective equipment (PPEs) and training are more likely to reduce health risks in work place, if effectively carried out on regular basis in work place. Workers that believed management are committed to employee safety and health are less likely to take risks and more likely to adhere to the employer's safety contract (Ford \& Tetrick, 2011; Hambach et al., 2011).

In a study conducted in eastern Nigeria Concerning the knowledge and practice of hand hygiene, $56.7 \%$ of the health workers knew that their hands had to be washed before and after patient care. However, compliance with hand hygiene was noticed in a mere thirty nine percent of the knowledgeable medical experts. Three (3\%) did not wash their hands before or after taking care of patients. This was an indication that the level of knowledge and implementation of standard precaution is unacceptably below standard to guarantee infection safety in health workers and patients, Uthman et al. (2012). Level of awareness of universal precautions increased with longer year of service in the health care sector (Vaz et al., 2007).

The findings of international labour organization (2008) in the USA about the inspiring element by employers in implementing safety measures were in contrast to what Goetzel identified in the UK. The cost of ill health and injury motivated USA employers to adopt safety culture. According to Dorman (2000), for an effective implementation of safety and health interventions in an organization, the cost of ill health and injury needs to be economic internalized, visible and variable, this will prompt the early implementation of OSH measures. 


\section{METHODOLOGY}

The cross-sectional survey research study was based on data from 80 (Cooper, \& Schindler, 2011) medical staff collected using a structured questionnaire from Baringo county referral hospital in Kenya. Baringo County lies between Latitudes 00 degrees 13" South and 1 degree $40 "$ north and Longitude 35 degrees 36" and 36" degrees 30" East with a population of 555,561 (Census, 2009).

Data was diagnostically screened so as to determine its suitability for factor analysis. The Kaiser-Meyer-Olkin (KMO) was used to determine the Measure of Sampling Adequacy for the overall data set was whereas Bartlett's test of sphericity was used for detection adequacy of correlations between the variables for variables to be reduced to a smaller number of components. Factor analysis was used as a dimension reduction technique to identify predictors and principal components that accounted most for adoption of occupations safety and health practices among health care workers in Kenyan public referral hospitals. Wald Chi-square test of model fit in a generalized linear model was used to determine if predictors in the principal components significantly influenced the adoption of occupational safety and health practices among staff in medical institutions in Kenya. Regression analysis was used to determine the relationship between principal components established through factor analysis.

\section{RESULTS AND DISCUSSION \\ Prioritization of Factors Influencing adoption of occupational safety and health practices}

Principal Component Analysis (PCA) procedure was used to investigate which factors contributed most adoptions of occupational safety and health practices among the medical staff in public medical institutions in Kenya. Initially, the factorability of the 20 items in the instrument was examined. The data was screened so as to determine its suitability for factor analysis. Firstly, it was established that based on the Kaiser-Meyer-Olkin (KMO) Measure of Sampling Adequacy for the overall data set was .538 (Kaiser \& Cerny, 1977). In order to ensure adequate correlations between the variables for variables to be reduced to a smaller number of components, Bartlett's test of sphericity was used for detection; the test was significant $\left(\chi^{2}\right.$ $(80)=780.3, p=.00<.05)$. Further the diagonals of the anti-image correlation matrix were also all over 0.5. With such indicators exhibiting such characteristics, factor analysis was deemed suitable for the analysis. Table 1 shows KMO and Barletts Test of Sphericity used to determine the factorability of the data.

Table 1: KMO and Barlett's Test of Sphericity

KMO and Bartlett's Test

\begin{tabular}{llr}
\hline Kaiser-Meyer-Olkin Measure of Sampling Adequacy. & .538 \\
\hline \multirow{3}{*}{ Bartlett's Test of Sphericity } & Approx. Chi-Square & 780.345 \\
& df & 190 \\
& Sig. & .000 \\
\hline
\end{tabular}

$\overline{\alpha=0.05}$ 
American Journal of Health, Medicine and Nursing Practice

ISSN 2520-4017 (Online)

Vol.4, Issue 1 No.1, pp 1 - 17, 2019

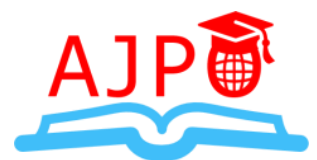

www.ajpojournals.org

To determine the number of components to retain, Kaiser Eigen value 1 criterion was used. (Kaiser, 1974). Going by this criteria six principal components with Eigen values greater than 1 were extracted. The result in Table 4.9 shows the percentage of variance accounted for by each of the 20 variables; suggesting the 20 variables in the key components measured in the seven latent factors accounted for $73.89 \%$ of the total variance observed in adoption of occupational safety and health practices among health care workers in Kenyan public referral hospitals.

Table 2: Total Variance Explained by Predictors of Employee Performance

Total Variance Explained

\begin{tabular}{|c|c|c|c|c|c|c|}
\hline \multirow[t]{2}{*}{ Component } & \multicolumn{3}{|c|}{ Initial Eigenvalues } & \multicolumn{3}{|c|}{ Extraction Sums of Squared Loadings } \\
\hline & Total & $\begin{array}{c}\% \text { of } \\
\text { Variance }\end{array}$ & $\begin{array}{c}\text { Cumulative } \\
\%\end{array}$ & Total & $\begin{array}{c}\% \text { of } \\
\text { Variance }\end{array}$ & $\begin{array}{c}\text { Cumulative } \\
\%\end{array}$ \\
\hline 1 & 4.962 & 24.812 & 24.812 & 4.962 & 24.812 & 24.812 \\
\hline 2 & 2.097 & 10.487 & 35.299 & 2.097 & 10.487 & 35.299 \\
\hline 3 & 2.057 & 10.283 & 45.582 & 2.057 & 10.283 & 45.582 \\
\hline 4 & 1.810 & 9.050 & 54.632 & 1.810 & 9.050 & 54.632 \\
\hline 5 & 1.535 & 7.673 & 62.305 & 1.535 & 7.673 & 62.305 \\
\hline 6 & 1.276 & 6.380 & 68.685 & 1.276 & 6.380 & 68.685 \\
\hline 7 & 1.043 & 5.213 & 73.898 & 1.043 & 5.213 & 73.898 \\
\hline 8 & .861 & 4.307 & 78.205 & & & \\
\hline 9 & .710 & 3.550 & 81.756 & & & \\
\hline 10 & .662 & 3.311 & 85.066 & & & \\
\hline 11 & .581 & 2.903 & 87.969 & & & \\
\hline 12 & .521 & 2.604 & 90.573 & & & \\
\hline 13 & .489 & 2.447 & 93.020 & & & \\
\hline 14 & .354 & 1.769 & 94.789 & & & \\
\hline 15 & .298 & 1.492 & 96.281 & & & \\
\hline 16 & .264 & 1.318 & 97.599 & & & \\
\hline 17 & .194 & .970 & 98.569 & & & \\
\hline 18 & .129 & .645 & 99.214 & & & \\
\hline 19 & .104 & .522 & 99.736 & & & \\
\hline 20 & .053 & .264 & 100.000 & & & \\
\hline
\end{tabular}

Extraction Method: Principal Component Analysis.

Results in Table 2 indicate seven latent components influence adoption of occupational safety and health practices among health care workers in Kenyan public referral hospitals. The seven components retained for meeting the Kaiser criteria of having Eigen values greater than 1 account for $73.898 \%$ of the total variance observed (Kaiser, 1974). 
In order to determine how many factors to retain, the resultant Cattell scree plot was examined, variables that loaded before the curve start to flatten and with Eigen values above one were retained. Figure 1 shows the resultant loading of Variables on the components displaying plotting Eigen value (y axis) against each component (x axis).

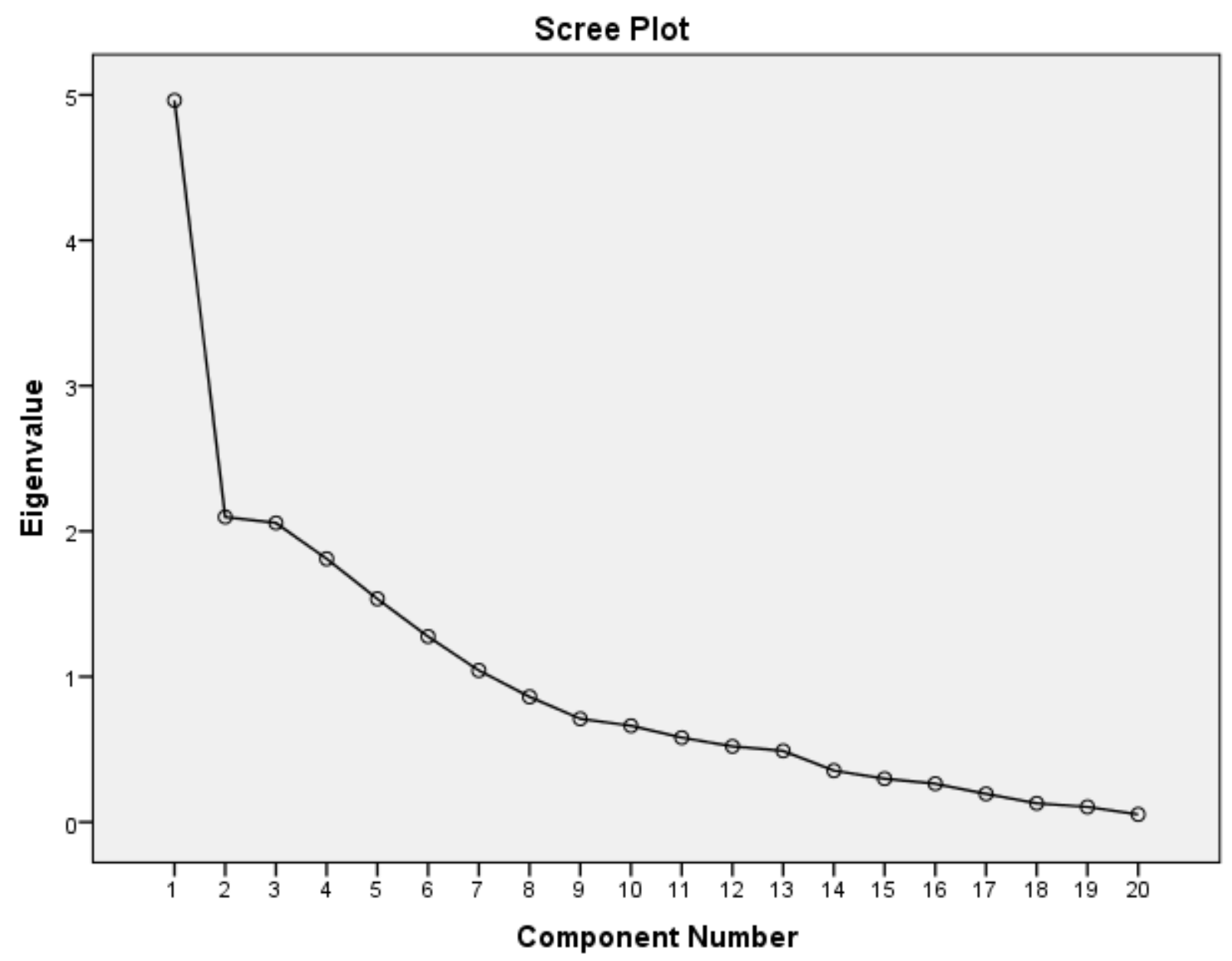

\section{Figure 1: Loading of Variables on the Components}

It is observed that the scree plot curve begins to flatten between factors 6 and 7. It is also apparent from the curve that components from factor 8 forward have Eigen values of less than 1 , going by this criteria five components $(1,2,3,4,5,6$ and 7$)$ were retained. This result implies that the seven main components from the once studied have the greatest contribution to adoption of occupational safety and health practices among health care workers in Kenyan public referral hospitals while the rest contributes little (26.1\%).

In order to identify the variables with high loadings on each of the components, rotated component matrix was examined. Table 3 shows Loadings of attributes on principal components. 
American Journal of Health, Medicine and Nursing Practice

ISSN 2520-4017 (Online)

Vol.4, Issue 1 No.1, pp 1 - 17, 2019

www.ajpojournals.org

Table 3: Loadings of Attributes on Principal Components

Component Matrix ${ }^{\mathrm{a}}$

\begin{tabular}{|c|c|c|c|c|c|c|c|}
\hline & \multicolumn{7}{|c|}{ Component } \\
\hline & 1 & 2 & 3 & 4 & 5 & 6 & 7 \\
\hline $\begin{array}{l}\text { Accessibility of SH } \\
\text { Guidelines }\end{array}$ & .742 & & & & & & \\
\hline Staff Training & .740 & & & & & & \\
\hline $\begin{array}{l}\text { Orientation on Laws and } \\
\text { Regulations Applicable }\end{array}$ & .671 & & .503 & & & & \\
\hline $\begin{array}{l}\text { Provision of Appropriate } \\
\text { Equipment's }\end{array}$ & .667 & -.402 & & & & & \\
\hline $\begin{array}{l}\text { Use of PPEs to Reduce } \\
\text { Injuries }\end{array}$ & .658 & & & & & & \\
\hline $\begin{array}{l}\text { Provision of Colour } \\
\text { Coded Disposal Bins }\end{array}$ & .599 & & -.498 & & & & \\
\hline $\begin{array}{l}\text { Easy Accessibility to } \\
\text { SOPs }\end{array}$ & .561 & -.445 & & & & & \\
\hline Provision of Safety Gear & .537 & & & & & & \\
\hline $\begin{array}{l}\text { Implementation of SH } \\
\text { Guidelines }\end{array}$ & .413 & -.630 & & & & & \\
\hline $\begin{array}{l}\text { Review of SH } \\
\text { Guidelines }\end{array}$ & .479 & -.497 & & .465 & & & \\
\hline Availability of PPEs & & -.422 & .411 & & & & \\
\hline Sensitization on Risks & & & .565 & & & & -.436 \\
\hline Wearing of Safety Gear & .528 & & -.530 & & & & \\
\hline $\begin{array}{l}\text { Communication of SH } \\
\text { Guidelines }\end{array}$ & .411 & & .418 & & & & \\
\hline $\begin{array}{l}\text { Provision of SOP on } \\
\text { PPEs }\end{array}$ & & & & .664 & & & \\
\hline $\begin{array}{l}\text { Availability of Risk } \\
\text { Assessment Officer }\end{array}$ & .437 & .537 & & .599 & & & \\
\hline $\begin{array}{l}\text { Provision of Adequate } \\
\text { Working Space }\end{array}$ & .459 & .509 & & .528 & & & \\
\hline TNA & & & & & .594 & .439 & \\
\hline Information Provision & & & & & .494 & -.568 & \\
\hline $\begin{array}{l}\text { Availability of SH } \\
\text { Guidelines }\end{array}$ & & & & & & .533 & \\
\hline
\end{tabular}

Extraction Method: Principal Component Analysis. 


\section{a. 7 components extracted.}

From the result in Table 4.10, the first latent principal component appears to measure "Staff capacity building (training)" and accounts for $24.87 \%$ of the variance (Eigen value $=4.962$ ). The second latent principal component was labelled "Implementation of Safety and Health guidelines" and accounts for $10.5 \%$ of the variance (Eigen value $=2.097$ ). The third latent principal component appears to measure "Wearing of Safety gear" which accounts for $10.3 \%$ of the variance (Eigen value=2.057). The fourth latent principal component appears to measure "Provision of Standard operating Procedures on PPEs" and accounts for $9.1 \%$ of the variance (Eigen value $=1.810$ ). The fifth latent principal component appears to measure "Training needs analysis" and accounts for $7.7 \%$ of the variance (Eigen value=1.535). The sixth latent principal component appears to measure "Provision of information to staff on guidelines" and accounts for $6.4 \%$ of the variance (Eigen value=1.276).. The seventh and last latent principal component appears to measure "Sensitization on risks" and accounts for $5.2 \%$ of the variance (Eigen value $=1.043$ ).

From the foregoing, the seven most critical factors influencing adoption of occupational safety and health practices among health care workers in Kenyan public referral hospitals: staff capacity building (training), implementation of safety and health guidelines, wearing of safety gear, provision of standard operating procedures on PPEs, training needs analysis, provision of information to staff on guidelines and sensitization on risks.

\section{Predictors of Adoption of Occupational Safety and Health Practices}

To determine if predictors in the principal components significantly influenced the adoption of occupational safety and health practices among health care workers in Kenyan public referral hospitals, Wald Chi-square test of model fit in a generalized linear model was performed on the seven predictors in the principal components. It was established the predictors had significant influence $\left(\chi^{2}(80)=1856.8, p=.00<.05\right)$ on predicting adoption of occupational safety and health practices.

Table 4: Test of Model Effects and Parameter Estimates

Parameter Estimates

\begin{tabular}{|c|c|c|c|c|c|c|c|c|}
\hline \multirow[t]{2}{*}{ Parameter } & \multirow[t]{2}{*}{ B } & \multirow[t]{2}{*}{$\begin{array}{l}\text { Std. } \\
\text { Error }\end{array}$} & \multicolumn{2}{|c|}{$\begin{array}{l}\text { 95\% Wald Confidence } \\
\text { Interval }\end{array}$} & \multicolumn{4}{|c|}{ Hypothesis Test } \\
\hline & & & Lower & Upper & $\begin{array}{l}\text { Wald Chi- } \\
\text { Square }\end{array}$ & df & & Sig. \\
\hline (Intercept) & 1.050 & .0244 & 1.002 & 1.098 & 1856.842 & & 1 & .000 \\
\hline (Scale) & $.047^{\mathrm{a}}$ & .0075 & .035 & .065 & & & & \\
\hline
\end{tabular}

Dependent Variable: Adoption of OSH Practices

a. Maximum likelihood estimate. 
American Journal of Health, Medicine and Nursing Practice

ISSN 2520-4017 (Online)

Vol.4, Issue 1 No.1, pp 1 - 17, 2019

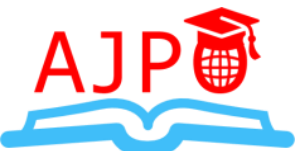

www.ajpojournals.org

\section{Relationship between Principal Components}

The study sought to determine the relationship been wearing of safety gear and the other six principal components.

\begin{tabular}{|c|c|c|c|c|c|c|c|c|c|}
\hline & & & & Model St & Immary $^{c}$ & & & & \\
\hline \multirow[t]{2}{*}{ Model } & \multirow[t]{2}{*}{$\mathrm{R}$} & \multirow{2}{*}{$\begin{array}{c}\text { R } \\
\text { Square }\end{array}$} & \multirow{2}{*}{$\begin{array}{c}\text { Adjusted } \\
\text { R } \\
\text { Square }\end{array}$} & \multirow{2}{*}{$\begin{array}{c}\text { Std. } \\
\text { Error of } \\
\text { the } \\
\text { Estimate }\end{array}$} & \multicolumn{5}{|c|}{ Change Statistics } \\
\hline & & & & & $\begin{array}{c}\text { R } \\
\text { Square } \\
\text { Change }\end{array}$ & $\begin{array}{c}\text { F } \\
\text { Change }\end{array}$ & df1 & df 2 & $\begin{array}{c}\text { Sig. F } \\
\text { Change }\end{array}$ \\
\hline 1 & $.316^{\mathrm{a}}$ & .100 & .088 & 1.458 & .100 & 8.670 & 1 & 78 & .004 \\
\hline 2 & $.327^{\mathrm{b}}$ & .107 & .096 & 1.452 & .107 & 9.355 & 1 & 78 & .003 \\
\hline
\end{tabular}

a. Predictors: (Constant), Staff Training

b. Predictors: (Constant), Implementation of SH Guidelines

c. Wearing of Safety Gear

The result on regression model established that staff training $\left(\mathrm{R}^{2}=.088, \Delta \mathrm{R}^{2}=0.100\right)$ and implementation of safety and health guidelines $\left(\mathrm{R}^{2}=.096, \Delta \mathrm{R}^{2}=0.107\right)$ were significant predictors of wearing of safety gear $\mathrm{F}(1,78)=8.670>3.84$, p-value $.004<0.05$, 95\% CI [.135, $.700], \mathrm{t}(79)=2.944$ and $\mathrm{F}(1,78)=9.355>3.84$, p-value $.003<0.05$, 95\% CI $[.123, .580]$, $\mathrm{t}(79)=3.059$ on training and implementation of safety and health guidelines respectively. A unit change in training will result a .316 change in wearing of safety gear while a unit change in the implementation of safety and health guidelines will result in .327 change in wearing of safety gear.

The study also sought to determine whether training which was established through factor analysis as having the highest contribution to adoption of safety and health had significant relationship with the other six elements in the principal components.

Model Summary ${ }^{\mathbf{a}}$

\begin{tabular}{|c|c|c|c|c|c|c|c|c|c|}
\hline \multirow[t]{2}{*}{ Model } & \multirow[t]{2}{*}{$\mathrm{R}$} & \multirow{2}{*}{$\begin{array}{c}\mathrm{R} \\
\text { Square }\end{array}$} & \multirow{2}{*}{$\begin{array}{l}\text { Adjusted } \\
\text { R Square }\end{array}$} & \multirow{2}{*}{$\begin{array}{l}\text { Std. Error } \\
\text { of the } \\
\text { Estimate }\end{array}$} & \multicolumn{5}{|c|}{ Change Statistics } \\
\hline & & & & & $\begin{array}{c}\text { R Square } \\
\text { Change }\end{array}$ & $\begin{array}{c}\text { F } \\
\text { Change }\end{array}$ & df1 & df 2 & $\begin{array}{c}\text { Sig. F } \\
\text { Change }\end{array}$ \\
\hline 1 & $.232^{\mathrm{b}}$ & .054 & .041 & 1.391 & .054 & 4.419 & 1 & 78 & .039 \\
\hline 2 & $.222^{\mathrm{c}}$ & .049 & .037 & 1.064 & .049 & 4.041 & 1 & 78 & .048 \\
\hline 3 & $.316^{\mathrm{d}}$ & .100 & .088 & 1.458 & .100 & 8.670 & 1 & 78 & .004 \\
\hline
\end{tabular}

a. Predictors: (Constant), Staff Training

b. Implementation of Safety and Health Guidelines

c. Sensitization on Risks

d. Wearing of Safety Gear

The result established that staff training predicted implementation of safety and health guidelines $\mathrm{R}^{2}=.041, \Delta \mathrm{R}^{2}=0.054, \mathrm{~F}(1,78)=4.419>3.84$, p-value $.039<0.05$, $95 \%$ CI [ .015 , 
$.554], \mathrm{t}(79)=2.102$ sensitization of workers $\mathrm{R}^{2}=.037, \Delta \mathrm{R}^{2}=0.049, \mathrm{~F}(1,78)=4.041>3.84$, $\mathrm{p}$ value $.048<0.05,95 \% \mathrm{CI}[.002, .414], \mathrm{t}(79)=2.010$ and wearing of safety gears $\mathrm{R}^{2}=.088, \Delta \mathrm{R}^{2}$ $=0.100, \mathrm{~F}(1,78)=8.670>3.84, \mathrm{p}$-value $.004<0.05,95 \%$ CI $[.135, .700], \mathrm{t}(79)=2.944$.

From the foregoing, results are consistent with those of Robson et al. (2012) who stated that training interventions aimed at improving the skills of employee on matters of OSH are influenced by the individual factors that include the learning style, cognitive ability, attitude and previous training. The immediate outcomes achieved from training are change in behaviour, attitude, enhance skills and motivation to act. These changes help in total control or minimization of hazard injuries, illness, machines and material damages, disabilities and costs associated with them.

Cohen \& Colligan (1998) indicated that safety and health training at the workplace should be incorporated in the safety and health policies. This will give assurances of the organization's commitment to continually ensure its staff understands their work, hence reduces chances of accidents and injuries. Amponsah-Tawiah \& Mensah (2016) supports that health and safety programs need a clear definition of the policies and how the training will take place to ensure safety performance. Amposah-Tawiah \& Mensah (2016) believe that by effectively training employees, they become more accountable and ensure safety at their workplace. Lastly Oluoch (2015) indicated that employers have an obligation to train staff, provide 10 knowledge and experience to its staff on the safety and wellbeing of the employee in the workplace.

The result further concurs with Steve, (2003) who stated that protective devices when performing risky activities and maintenance of safe place of work are necessary precautionary measures against accidents. Kuhn, (2015) concluded that insufficient evidence exists to draw conclusions regarding the comparative effectiveness of various types of personal protective equipment. Additional research is urgently needed to determine optimal PPE for health care workers caring for patients with filovirus. Also Lombardi, et al, (2018) indicated Several potentially modifiable factors identified would lead to an increase in workers' PPE use and encourage supervisors to provide ongoing positive feedback for the continuous use of PPE by workers at risk for an eye injury.

Similarly, the result is consistent with Olufemi et al, (2016) who posits that the goal of all occupational safety and health practices is to foster a safe work environment and protect coworkers, family members, employers, customers, suppliers, nearby communities, and other members of the public who are impacted by the workplace environment. In addition, the International Labor Organization, (2011) workplace accidents and errors cost organizations, hundreds of billions of dollars each year, and the injured workers and their families endure considerable financial and emotional suffering. In the reviewed OSH act 2007, workers are to abide by the guidelines, SOPs and regulations governing the workplace. The ministry of health has in provisions safety guidelines that govern all the operations and procedures to ensure safety at work place. 


\section{CONCLUSION}

It was concluded that from the total of 20 factors under study, seven factors accounted most in determining Adoption of occupational safety and health practices among health care workers in Kenyan public referral hospitals. These are staff capacity building (training), implementation of safety and health guidelines, wearing of safety gear, provision of standard operating procedures on PPEs, training needs analysis, provision of information to staff on guidelines and sensitization on risks.

It was also concluded that the main determinant in the adoption of occupational safety and health practices among health care workers in Kenyan public referral hospitals is Staff capacity building (training) and accounts for a quarter (24.87\%) of the reasons for adoption. Followed by Implementation of Safety and Health guidelines, Wearing of Safety gear, Provision of Standard operating Procedures on PPEs, Training needs analysis, Provision of information to staff on guidelines and Sensitization on risks in descending order.

It was also concluded that the seven factors were significant predictors of adoption of occupational safety and health practices and probably occupational injuries among health care workers.

\section{RECOMMENDATION OF THE STUDY}

Based on the findings of this study, the following recommendations were made:

i. County Executive Committee member for health through the Medical Superintendent should make necessary budgetary allocations towards staff training, organize and implement specialized training in occupational safety and health for their staff as a matter of priority. The contents of such specialized training should be informed by recommendations in training needs analysis reports.

ii. Medical Superintendent in charge of public referral hospitals should put in place a robust mechanism that ensures consistent implementation of safety and health guidelines in their facilities, a framework for effective monitoring, evaluation and reporting may help enhance such implementation.

iii. The Human Resource Officers should on continuous basis utilizing continuous education approach organised from time to time staff sensitization particularly to sensitize staff on wearing of safety gear, standard operating procedures on PPEs, preview of applicable guidelines and sensitization on risks.

iv. Medical Superintendent in charge of public referral hospitals should cause an audit of PPEs and ensure that deficits on PPEs are included in the next and subsequent financial year procurement plan.

\section{REFERENCES}

Adema, W. \& Ladaique, M. (2009), "How Expensive is the Welfare State?: Gross and Net Indicators in the OECD Social Expenditure Database (SOCX)", OECD Social, Employment and Migration Working Papers, No. 92, OECD Publishing.

Alli, B.O. (2008). Fundamental Principles of Occupational Health and Safety, $2^{\text {nd }}$ ed, ILO Geneva.

Amodu, M.O., Abdulraheem, I.S., Saka, M.J., Bolarinwa, O.A. \& Uthman, M.B. (2012) Knowledge, Awareness and Compliance with Standard Precautions among Health 
American Journal of Health, Medicine and Nursing Practice

ISSN 2520-4017 (Online)

Vol.4, Issue 1 No.1, pp 1 - 17, 2019

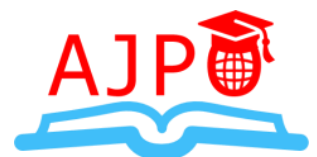

www.ajpojournals.org

Workers in North Eastearn Nigeria. Journal of Community Medical Health Education, 2:131

Amponsah-Tawiah, K. \& Dartey-Baah, K. (2011). Occupational health and safety: key issues and concerns in Ghana. International Journal of Business and Social Science, 2(14).

Annalee Y., Karen, L., Ray, C., Mickey, K. \& Marc Corbiere, E. (2007). Determinants of Healthcare Workers' Compliance with Infection Control Procedures. Healthcare Quarterly, 10(1), 44-52.

Arocena, P., Núñez, I. \& Villanueva, M. (2008). The impact of prevention measures and organisational factors on occupational injuries. Safety Science, 46(9), 1369-1384.

Brewer, M., Browne, J., Joyce, R. \& Payne, J. (2010). Child and working-age poverty from 2010 to 2020. London: Institute for Fiscal Studies.

Brunner, G.H. \& Suddarth's, S.C. (2007). Textbook of Medical-Surgical Nursing, 12 ${ }^{\text {th }}$ ed. Pennsylvania: Lippincott William \& Wilkins Company.

Bunn, W.B., Pkelmy, D.B., Slavn, J.J. \& Parakar, S. (2001). Health, safety and productivity in a manufacturing environment, Journal of Occupational and Environmental Medicine 43:47-55.

Colligan, M. J. \& Cohen, A. (1998). The role of training in promoting workplace safety and health. The psychology of workplace safety, 223-248.

Cooper, D.R. \& Schindler, P. S. (2011). Qualitative research. Business research methods, 4(1), 160-182.

Doebbeling, N.B. \& Daniel, D.D. (1995). Employee Health and Infection, Infection Control and Hospital Epidemiology, 16(5), 292-301

Ford, M. T. \& Tetrick, L. E. (2011). Relations among occupational hazards, attitudes, and safety performance. Journal of Occupational Health Psychology, 16(1), 48.

Forst, L., Avila, S., Anozie, S. \& Rubin, R. (2010). Traumatic Occupational Injuries in Hispanic and Foreign Born Workers. American Journal of Industrial Medicine, 53, 344-351. DOI:10.1002/ajim.20748

Hale, S. (2004). Managing light to enable natural regeneration in British conifer forests. Forestry Commission.

Hambach, U., Buggle, B., Glaser, B., Gerasimenko, N., \& Marković, S. (2011). An evaluation of geochemical weathering indices in loess-paleosol studies. Quaternary International, 240(1-2), 12-21.

Håvold, J.I. \& Nesset, E. (2009). 'From safety culture to safety orientation: Validation and simplification of a safety orientation scale using a sample of seafarers working for Norwegian ship owners', Safety Science, 47, pp. 305-326.

International Labor Organization (ILO) (2011). ILO Introductory Report: Global Trends and Challenges on Occupational Safety and Health. Geneva: International Labour Office

Joan, B (2010). Language, usage and cognition. Cambridge University Press.

Kuhn, M. (2015). Caret: classification and regression training. Astrophysics Source Code Library.

Kurt, E., Dede, S. \& Ragbetli, C. (2010). The Investigations of Total Antioxidant Status and Biochemical Serum Profile in Thymoquinone-Treated Rats. Tradit Complement Altern Med. 12(2):68-72.

Lombardia, A. R. (2018). Arpa Lombardia. particolare, il decreto, 5522(09).

Manyele, S.V, Ngonyani, H.A. \& Eliakimu, E. (2008). The Status of occupational safety among health services providers in hospitals in Tanzania. Tanzania Journal of Health, Research, 10 (3), pp. 159-165. 
American Journal of Health, Medicine and Nursing Practice

ISSN 2520-4017 (Online)

Vol.4, Issue 1 No.1, pp 1 - 17, 2019

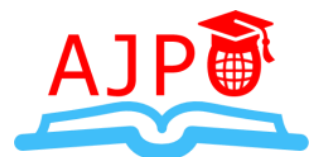

www.ajpojournals.org

Matsiko, C. W. (2010). Positive practice environments in Uganda: Enhancing health worker and health system performance. International Council of Nurses, International Pharmaceutical Federation, World Dental Federation, World Medical Association, International Hospital Federation, World Confederation for Physical Therapy/Global Health Workforce Alliance. Geneva, Switzerland

Melisa, B.D. (2014). Cobb-Clark and Mark Wooden, Job loss and the mental health of spouses and adolescent children, IZA Journal of Labour Economics, 1,(6), 1-24

Ndejjo, R., Mukama, T., Musabyimana, A. \& Musoke, D. (2016) Uptake of Cervical Cancer Screening and Associated Factors among Women in Rural Uganda: A Cross Sectional Study. PLoS ONE 11(2): e0149696. https://doi.org/10.1371/journal.pone.0149696

O'Connor, T., Flynn, M., Weinstock, D., \& Zanoni, J. (2014). Occupational safety and health education and training for underserved populations. New solutions: A Journal of Environmental and Occupational Health Policy, 24(1), 83-106. DOI: 10.2190/NS.24.1.d

Olufemi, P., Ogunsola, G., Salman, K. (2015). Technical Efficiency of Cocoa Production in Southwest Nigeria. International Journal of Agriculture, Food Res. 4(4), 1-14

Oluoch, D. A. (2015). "You cannot know if it's a baby or not a baby": uptake, provision and perceptions of antenatal care and routine antenatal ultrasound scanning in rural Kenya. BMC pregnancy and childbirth, 15(1), 127.

Orme, C., Mitruka, K., Thornton, K., Cusick, S., Moore, A., Manch, R. A. \& Ward, J. W. (2014). Expanding primary care capacity to treat hepatitis $C$ virus infection through an evidence-based care model-Arizona and Utah, 2012-2014. MMWR. Morbidity and mortality weekly report, 63(18), 393.

Occupational Safety and Health. (2007). towards an occupational safety and health culture. Availavle at, https://oshwiki.eu/index.php.

Robson, L., Stephenson, C., Schulte, P., Amick, B., Chan, S., Bielecky, A., Wang, A., Heidotting, T., Irvin, E., Eggerth, D., Peters, R., Clarke, J., Cullen, K., Boldt, L., Rotunda, C., \& Grubb, P. (2012). A systematic review of the effectiveness of training and education for the protection of workers. Toronto, Ontario, Canada: Institute for Work and Health

Rono W.C. (2011). Factors that influence Adoption of Employees Wellness Programs at the Standard Group Limited. Unpublished MBA Research Project, University of Nairobi.

Steve E. (2003). An exploration of the right and obligation to refuse unsafe working conditions

World Health Organization \& Burton, Joan. (2010). WHO healthy workplace framework and model: background and supporting literature and practices. World Health Organization. https://apps.who.int/iris/handle/10665/113144 